\title{
Um olhar liberal sobre a América Latina
}

\author{
Lara D'Assunção dos Santos
}

\section{(2) OpenEdition}

\section{Journals}

Edição electrónica

URL: http://journals.openedition.org/espacoeconomia/472

DOI: 10.4000/espacoeconomia.472

ISSN: 2317-7837

\section{Editora}

Núcleo de Pesquisa Espaço \& Economia

\section{Refêrencia eletrónica}

Lara D'Assunção dos Santos, «Um olhar liberal sobre a América Latina », Espaço e Economia [Online], 3 | 2013, posto online no dia 18 dezembro 2013, consultado o 22 setembro 2020. URL : http:// journals.openedition.org/espacoeconomia/472 ; DOI : https://doi.org/10.4000/espacoeconomia.472

Este documento foi criado de forma automática no dia 22 setembro 2020.

(c) NUPEE 


\title{
Um olhar liberal sobre a América Latina
}

\author{
Lara D’Assunção dos Santos
}

\section{REFERÊNCIA}

REID, Michael. o continente esquecido: a batalha pela alma latino-americana. Rio de Janeiro: Campus/Elsevier (2008 [2007]). Tradução do original em inglês: Marcello Lino. 396p.

1 Editor da seção "Américas" da revista britânica The Economist, Michael Reid trabalhou como jornalista correspondente no Peru, no México e no Brasil, onde reuniu material e experiência para a redação de $O$ continente esquecido: A batalha pela alma latino-americana. Com a difícil missão de atingir o grande público, o autor inicia com um breve da história do século XIX para embasar seus argumentos a favor da onda democrática que a América Latina se encontra atualmente.

2 A crítica principal de Reid é fundamentada na necessidade de conhecermos a história da América Latina para além das fronteiras de seus Estados Nacionais. Em artigo recente publicado na Polis, Revista Latinoamericana, os geógrafos brasileiros Carlos Walter Porto-Gonçalves e Pedro Quental recuperam as reflexões de Walter Mignolo e apontam que "o conceito de América - e, posteriormente América Latina - é uma construção semântica com implicações políticas, econômicas, epistêmicas e éticas que surgiu e se impôs em detrimento de conceitualizações e denominações originárias deste mesmo continente" (PORTO-GONÇALVES \& QUENTAL, 2012:3). Assim, é preciso sempre destacar que a noção de "continente latino-americano", forjada de cima para baixo por epistemologias eurocêntricas (vide MIGNOLO, 2003), traz consigo fortes simplificações, já que culturas, povos e tradições distintas foram reunidas sob uma representação homogênea. Afinal, os "latino-americanos" se sentem e se vêem como latinoamericanos? No caso brasileiro, não é difícil constatar certo desconhecimento diante da história de nossos vizinhos. Tal situação pode estar ligada ao fato da maioria dos 
brasileiros não se sentir parte integrante da América Latina - seja por que não falam a língua da maioria ou, simplesmente, por que não acreditam em uma América Latina? Para Michael Reid, essa identidade existe e corresponderia às mazelas sociais e às ditaduras militares que marcaram a vida política da região.

No decorrer da leitura, torna-se evidente que o título 0 continente esquecido não pode ser atribuído apenas aos processos de violência e de expropriação promovidos pelos países centrais, mas também às elites políticas e econômicas que governaram as nações latinoamericanas. Segundo Reid, existe uma lacuna por parte da população a respeito da história de seu próprio continente, algo que pode ser creditado, entre outros aspectos, aos alinhamentos geopolíticos em direção à Europa e aos Estados Unidos - e, acrescentaríamos, à própria constituição das narrativas histórico-geográficas, que desvalorizam tudo aquilo que não pertence à Europa. $O$ continente não quer olhar para si, mas para o exterior, e, nesse movimento, não percebe interesses e questões alheios à sua realidade. $O$ resultado é a visível fragilidade da integração regional, bem como a difícil resolução de problemas comuns ${ }^{1}$.

Michael Reid tenta explicar o quadro político da América Latina à luz do populismo, forma de governo dominante na primeira metade do século XX, momento em que suas populações lutavam por significativas mudanças sociais. Muitas vezes, o populismo representou uma reação à desigualdade e ao domínio de grupos conservadores. No entanto, liderado por figuras fortes e carismáticas, o populismo pouco tinha de democrático, e as políticas econômicas dele oriundas ${ }^{2}$ não foram capazes de superar o quadro de subordinação e de dependência vivido pelas nações latino-americanas. Tal situação, evidentemente, não beneficiava a maioria da população, mas, por outro lado, favorecia enormemente os grupos econômicos hegemônicos que mantinham negócios com os países centrais (vide CARDOSO \& FALETTO, 1977 [1970]). Com o discurso de que Estados com riquezas naturais tão abundantes são pobres em função do imperialismo norte-americano e das perversas ações de empresas multinacionais, figuras como Hugo Chávez (Venezuela), Ollanta Humala (Peru) e Evo Morales (Bolívia) transmitem aos eleitores pobres e de pele escura a sensação de que eles estão sendo defendidos e fielmente representados. Segundo Reid, as democracias ainda não consolidadas (com exceção da Costa Rica e Uruguai), continuam a ser rondadas pelo "perigo populista" (REID, 2008:14 [2007]).

5 Aqui, as reflexões do intelectual peruano Aníbal Quijano - inútil esclarecer, autor que milita no campo político oposto ao do autor aqui resenhado - parecem traduzir a visão de Michael Reid sobre o então presidente da Venezuela, Hugo Chávez. A história de Dom Quixote de La Mancha, herói que vive em um modelo de servidão e luta contra "monstros" que, na realidade, são moinhos de vento representando a chegada de uma nova organização econômica - o capitalismo -, revela semelhanças com a política dos presidentes acima mencionados. Para Quijano, eles lutam constantemente contra "monstros", mas suas práticas políticas teimam em lograr relações paternalistas e assistencialistas e seus países convivem com novos e velhos modelos simultaneamente. Este misto entre o novo e o velho é intrínseco às relações de trabalho e às paisagens latino-americanas (QUIJANO, 2005).

Reid também discorre sobre o pêndulo ditadura militar-governo civil em que a região se encontrava entre os anos de 1960 e 1980 até atingir o patamar de regimes democráticos. Pressionado pelos capitalistas, o Estado agia duramente às reinvidicações salariais locais, o que levaria inevitavelmente a ditaduras militares (REID, 2008:38 
[2007]). Na perspectiva estruturalista, os estrangeiros, o capitalismo e seus aliados eram responsáveis pelo quadro de pobreza vivido pela América Latina (vide PREBISCH, 1949). No capítulo quarto, Reid opõe-se à teoria da dependência, minimiza seu poder interpretativo - "por várias razões, a dependência não se configura como uma teoria explanatória - especialmento no âmbito econômico" (REID, 2008:41 [2007]) e argumenta que, além de equivocada, ela teve a infeliz consequência de incentivar os latino-americanos a situarem a culpa de todos os seus problemas na dominação estrangeira, em vez de olhar para si mesmos com mais atenção (idem, p.43). Destaca ele que tal teoria ainda exerce grande influência na mentalidade latino-americana, embora, nos anos sessenta, ela parecesse estar em sintonia com a realidade. Nesta época, empresas multinacionais americanas instalavam-se em diversos países provocando o fechamento de pequenas empresas locais, o que agravou o quadro de desemprego e exclusão social.

7 Reid cita o célebre livro do jornalista uruguaio Eduardo Galeano, As veias abertas da América Latina (GALEANO, 2010 [1971]), para explicar a permanência da teoria dependentista em nossa memória até os dias atuais. Segundo Reid, Galeano passa uma mensagem anticapitalista e antiimperialista ao justificar o nosso subdesenvolvimento com base no desenvolvimento dos outros países. A crítica de Reid ao livro de Galeano torna-se ainda mais veemente durante o sexto capítulo, "Ascensão e queda do consenso de Washington", quando ele inclina-se a um posicionamento político de direita. Este capítulo descreve a onda de privatizações vivida pelos países latino-americanos nos anos oitenta e noventa. Apesar das consequências sentidas nos anos posteriores, Reid parece apoiar a política econômica neoliberal, pois afirma que muitas foram as privatizações de sucesso, mas a população costuma associá-las à corrupção e às tarifas elevadas - quando comparadas ao serviço público oferecido anteriormente (REID, 2008:158 [2007]).

8 Atualmente, os eventos no Brasil - Rio + 20, Copa das Confederações, Jornada Mundial da Juventude, Copa do Mundo, Jogos olímpicos -, acrescidos do falecimento do venezuelano Hugo Chávez e a consagração de um papa argentino, fizeram com que os olhos do mundo inteiro estivessem atentos à América Latina. Tais acontecimentos atraem cada vez mais novos projetos para esta região e, de certa forma, acabam por "valorizar" a alma latino-americana. Contudo, a realidade vivida pela população pouco muda após esses "mega-eventos". O quadro latino-americano continua precário e desigual.

O livro de Reid foi publicado originalmente em 2007. No momento em que escrevemos essa resenha (junho-julho de 2013), o Brasil é tomado por manifestações populares de norte a sul do território. A reforma de nossos estádios de futebol em "arenas" luxuosas e modernas como condição imposta pela FIFA para a realização da Copa das Confederações em 2013 e da Copa do Mundo em 2014 e o elevado custo público destes empreendimentos, juntamente com o aumento do preço da passagem de ônibus em algumas das principais cidades do país, foram o estopim para uma série de reivindições populares que marcarão a história do Brasil nesse início do século XXI. Organizados através das redes sociais, a população tomou as ruas e ergueu cartazes que reinvidicavam melhorias na educação, na saúde, na segurança e no transporte público, exigindo o fim da corrupção e uma ampla reforma política. As passeatas traduzem o grito de indignação de todo o país; elas nos fazem recordar a advertência de que as 
democracias precisam deixar de apresentar um comportamento meramente delegativo (O'DONNELL, 2009).

10 Nas primeiras páginas do livro, Reid aborda a inversão do quadro rural para o urbano nos anos cinquenta. $\mathrm{O}$ descompasso entre o crescimento abrupto das cidades e os serviços públicos é a chave para entendermos a realidade caótica em que se encontram as cidades latino-americanas. Para ele, o fracasso latino-americano não foi o das reformas econômicas, mas daquilo que, em grande parte, não foi reformado: o Estado e as instituições públicas (REID, 2008:10 [2007]). 0 maior acesso à educação veio de mãos dadas com o processo de urbanização e, embora incipiente, foi o bastante para que a sociedade se tornasse mais ciente de seus direitos, exigindo cada vez mais dos governos (p. 239). Vem daí o título "Sociedades em mutação" dado ao nono capítulo do livro. Esta percepção do autor nos leva a supor que ele apoiaria os motivos dos protestos no Brasil, bem como desconfiaria da cobertura promovida pelas grandes empresas de comunicação. Embora ele diga que atualmente a Rede Globo tornou-se um "veículo muito mais democrático" (p.252), isto não o impediu de ressaltar que a mesma deveu

"sua expansão a seu relacionamento com a ditadura. A Globo notoriamente não cobriu as maciças demonstrações de rua que reividicavam eleições presidenciais diretas em 1985 (...) Em 1990, fez tudo o que podia para impedir que Lula vencesse a eleição presidencial e fazer com que Fernando Collor (...) fosse eleito em seu lugar." (pp. 251-252).

11 Para Reid, a notícia de que a América Latina encontram-se majoritariamente sob gestão de governos democráticos é o primeiro passo para futuras mudanças. No caso das democracias relativamente jovens como a do Brasil, alterações no âmbito dos partidos políticos e na segurança pública devem ser realizadas. A fragilidade de ambos por estarem constantemente envolvidos em esquemas de corrupção e por atuarem em prol de interesses privados resulta na principal marca das democracias incipientes: a vulnerabilidade das instituições centrais.

Enfim, o liberal Michael Reid afirma que uma democracia forte tende ao bipartidarismo, tal como ocorre na Europa e nos Estados Unidos. Presidente da República Dominicana pela segunda vez em 2004, Leonel Fernández apresenta-se como um incentivador desta tendência: "um déficit fiscal não é de direita e nem de esquerda, mas um problema de gestão" (p. 12). Assim, a representatividade dos partidos brasileiros, que, em 2006, contava com vinte e um legendas na Câmara dos Deputados, sendo a maior o PMDB com $17 \%$ do Parlamento (p. 314), pode ser posta em xeque. Na atual realidade brasileira, não percebemos mais ideologias partidárias. Deputados trocam constantemente de partido mesmo após eleitos, e presidentes tidos como de esquerda não dão atenção a problemas como a reforma agrária.

Michael Reid desfecha o livro de maneira otimista, confiante na evolução das jovens democracias latino-americanas mas apontando que cada passo rumo às mudanças será árduo. Contudo, a América Latina nunca esteve tão próxima de alcançá-las. 


\section{BIBLIOGRAFIA}

CARDOSO, Fernando Henrique, FALETTO, Enzo. Dependência e desenvolvimento na América Latina. $4^{\mathrm{a}}$ ed. Rio de Janeiro: Zahar Editores (1977 [1970]).

GALEANO, Eduardo. O elogio da desobediência. In: MINÀ, Gianni. o continente desaparecido. Os ideais de Porto Alegre que estão mudando a América Latina. Rio de Janeiro: Record (2007 [2005]). As veias abertas da América Latina. Porto Alegre: L \& PM (2010 [1971]).

MIGNOLO, Walter. Histórias locais/projetos globais: colonialidade, pensamento liminar e saberes subalternos. Belo Horizonte: Editora da UFMG (2003 [2000]).

O'DONNELL, Guillermo. Reflexões sobre as democracias sul-americanas contemporâneas. In: DUPAS, Gilberto, LAFER, Celso, SILVA, Eduardo Lins. (orgs). A nova configuração mundial do poder. São Paulo: Paz e Terra (2008).

OLIVEIRA, Francisco de. Crítica à razão dualista/O ornitorrinco. São Paulo: Boitempo, 2003 (1972). PORTO-GONÇALVES, Carlos Walter, QUENTAL, Pedro. Colonialidade do poder e os desafios da integração regional na América Latina. Polis [En línea], 31 (2012).

PRÉBISCH, Raul. O desenvolvimento econômico da América Latina e seus principais problemas. Revista Brasileira de Economia, vol. 3, set. (1949).

QUIJANO, Aníbal. Dom Quixote e os moinhos de vento na América Latina. Estudos avançados [online], vol.19, n.55 (2005).

REID, Michael. $O$ continente esquecido: a batalha pela alma latino-americana. Rio de Janeiro: Elsevier (2008 [2007]).

\section{NOTAS}

1. Contudo, tal conjuntura vem mudando nas últimas duas décadas. Vimos a importante formação do Fórum Social Mundial no ano de 2001 realizado em Porto Alegre como contraponto ao encontro dos países mais poderosos, o Fórum Econômico Mundial de Davos. Nas edições daquele Fórum, temas como desenvolvimento, meio ambiente, direito dos povos, pobreza, conflitos armados e mudanças políticas foram discutidas com o intuito de "lembrar" a existência do continente latino-americano ou "o encontro dos desencontrados", como definiu Eduardo Galeano durante sua participação no Fórum em 2005 (GALEANO, 2007:50 [2005]).

2. No que concerne à articulação entre populismo e economia no Brasil e suas consequências em termos do aprofundamento das relações capitalistas, consulte a aguda interpretação de Francisco de Oliveira no célebre Crítica à razão dualista (OLIVEIRA, 2003 [1972]). 


\section{AUTORES}

\section{LARA D'ASSUNÇÃO DOS SANTOS}

Formanda em Geografia pela UFRRJ e monitora de Geografia Econômica desta instituição.

Vinculada ao Núcleo de Pesquisas Espaço e Economia (NuPEE) 